Article

\title{
Isolation and Identification of Anthocyanin Component in the Fruits of Acanthopanax Sessiliflorus (Rupr. \& Maxim.) Seem. by Means of High Speed Counter Current Chromatography and Evaluation of Its Antioxidant Activity
}

\author{
Liang Chen ${ }^{1}$, Xiulan Xin ${ }^{1, *}$, Hui Feng ${ }^{1}$, Shuangshi Li ${ }^{1}$, Qiguang Cao ${ }^{1}$, Xinying Wang ${ }^{2}$ \\ and Frank Vriesekoop ${ }^{3, * \mathbb{D}}$ \\ 1 College of Bioengineering, Beijing Polytechnic, Beijing 100176, China; chenliang@bpi.edu.cn (L.C.); \\ fenghui@bpi.edu.cn (H.F.); lishuangshi@bpi.edu.cn (S.L.); caoqiguang@bpi.edu.cn (Q.C.) \\ 2 MSD R\&D (China) Ltd. Co., Beijing 100029, China; wangxinying1986@gmail.com \\ 3 Department of Food Technology and Innovation, Harper Adams University, Newport TF10 8NB, UK \\ * Correspondence: xinxiulan@bpi.edu.cn (X.X.); fvriesekoop@harper-adams.ac.uk (F.V.); \\ Tel.: +44-1952-820-280 (F.V.)
}

Academic Editors: Monika Waksmundzka-Hajnos, Miroslaw Hawryl and Francesco Cacciola Received: 19 February 2020; Accepted: 10 April 2020; Published: 13 April 2020

\begin{abstract}
Acanthopanax sessiliflorus (Rupr. \& Maxim.) Seem. (Araliaceae) is one of the most abundant species of genus Acanthopanax. The fruits of $A$. sessiliflorus are used in traditional medical protocols as an analgesic, tonic, antidiabetic, antihypertensive, anti-inflammatory, antitumor, and immune-stimulating agent. In this work, we carried out a comprehensive investigation into the anthocyanin components in the fruits of $A$. sessiliflorus. The anthocyanin content in the fresh fruits of $A$. sessiliflorus was determined by high performance liquid chromatography-diode array detection (HPLC/DAD), and the anthocyanin component was isolated from these using high-speed counter-current chromatography (HSCCC) and elucidated by electro-spray ionization-mass spectrometry (ESI/MS), ${ }^{1} \mathrm{H}$ - and ${ }^{13} \mathrm{C}$-NMR. Its antioxidant activity was evaluated by ferric-reducing antioxidant power (FRAP) and 2,2-diphenyl-1-picrylhydrazyl (DPPH). We found that A. sessiliflorus contained a gross anthocyanin content of $121.35 \mathrm{mg} / 100 \mathrm{~g}$. HSCCC was successfully used for separation and purification of the primary anthocyanin component, cyanidin 3-xylosyl-galactoside. The antioxidant and radical scavenging tests indicated that cyanidin 3-xylosyl-galactoside is a potent antioxidant.
\end{abstract}

Keywords: anthocyanin; Acanthopanax sessiliflorus (Rupr. \& Maxim.) Seem.; high-speed counter-current chromatography (HSCCC); antioxidant activity

\section{Introduction}

Acanthopanax sessiliflorus (Rupr. \& Maxim.) Seem. (Araliaceae) (Figure 1) is one of the most abundant species of genus Acanthopanax, which is a perennial plant native to the northeast region of China, Japan, and Korea. The roots, stems, and leaves of A. sessiliflorus elicit a range of biological functions, including antipancreatic lipase, antiplatelet aggregation, and anti-inflammatory effects [1-4]. Various parts from the plant are used in a wide range of traditional medical applications, including the roots, shoots, bark, leaves, and fruits [2,5-10]. The fruits of $A$. sessiliflorus are used in traditional medical protocols as an analgesic, tonic, antidiabetic, antihypertensive, anti-inflammatory, antitumor and immune-stimulating agent [5-7]. 


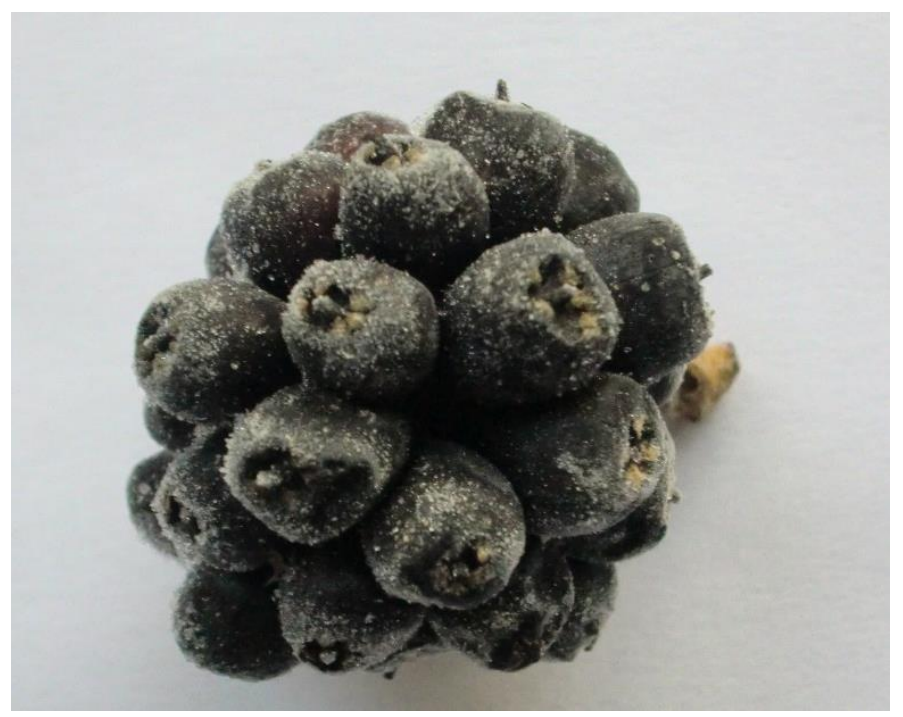

Figure 1. Fruits from Acanthopanax sessiliflorus (Rupr. \& Maxim.) Seem.

Many different compounds were extracted and identified from the dried materials of A. sessiliflorus fruits for their biological functions, identified as seopoletin, isofraxidin, hyperin, scoparone, protocatechuic acid, ursolic acid, oleanic acid, chiisanogenin, sesamin, daucosterol, $\beta$-sitosterol, etc. [11-15]. While most of the above-mentioned compounds provide potential health benefits in terms of analgesic, anticoagulant, or anti-inflammatory actions, only very few antioxidant compounds were identified. An unidentified compound (AE-7-CII) from A. sessiliflorus possessing an antioxidative profile and characterized as both an $\mathrm{O}^{2-}$ inhibitor and scavenger was described [16]. Up to now, few reports exist regarding anthocyanin analysis in fresh A. sessiliflorus fruits. Anthocyanins provide the skins of fruits with colors varying from purple to black and possess a multitude of biological properties, e.g., antidiabetic, anti-inflammatory and antitumor properties [17].

High-speed counter-current chromatography (HSCCC) is an innovative technique used for scale-up separation with minimum sample preparation and permits both normal- and reversed-phase operation [18]. HSCCC is a support-free liquid-liquid partition chromatographic technique shown to be a useful tool for the purification of compounds from natural products [19-23]. As such, HSCCC has some major advantages over more traditional liquid-solid chromatography by eliminating the various complications caused by the solid support matrix, such as adsorptive loss and deactivation of samples, tailing of solute peaks, contamination, etc. It is a relatively simple (low-pressure method) technology and has a relatively low cost of operation due to its use of technical-grade solvents [24]. Finally, it has an excellent yield capacity with a phenomenal sample recovery.

In this study, the anthocyanin content in the fresh fruits of $A$. sessiliflorus was determined by HPLC/DAD, and the anthocyanin component was isolated from these using HSCCC and elucidated by ESI/MS, ${ }^{1} \mathrm{H}$ - and ${ }^{13} \mathrm{C}-\mathrm{NMR}$. Antioxidant activity was evaluated by 2,2-diphenyl-1-picrylhydrazyl (DPPH) and ferric-reducing antioxidant power (FRAP).

\section{Results and Discussion}

\subsection{Total Anthocyanin Determination}

The gross anthocyanin content was $121.35 \mathrm{mg} / 100 \mathrm{~g}$, expressed as milligrams of cyanidin 3 -glucoside per $100 \mathrm{~g}$ of fresh weight by HPLC-DAD. The primary peak (Figure 2) occupied $95.4 \%$ of the total peak area and other anthocyanin components were present at trace levels only. Based on the UV-Vis spectrum of the primary peak, the maximum absorbance was $520 \mathrm{~nm}$, which is typical of anthocyanins [25,26]. The absorbance between 310 and $360 \mathrm{~nm}$ (Figure 2) suggested that the compound might not be acylated [27]. The absorbance ratio at $440 \mathrm{~nm}$ to the absorbance of the visible maximum 
wavelength for the primary peak $\left(\mathrm{A}_{440 \mathrm{~nm}} / \mathrm{A}_{\lambda \max }\right.$ ratio) was found to be $30.08 \%$, indicating that this compound is very likely glycosylated at the $\mathrm{C}-3$ position of the $\mathrm{C}$-ring $[28,29]$.

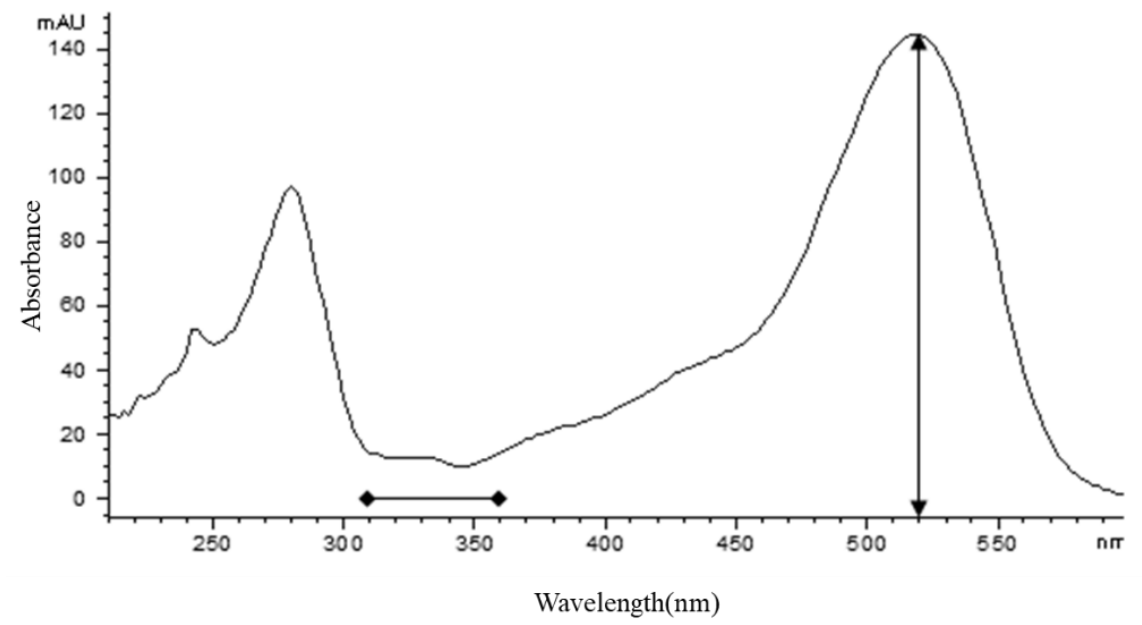

Figure 2. UV-Vis spectrum of the primary peak. The maximum absorbance at $520 \mathrm{~nm}$. The lack of absorbance in the region between 310 and $360 \mathrm{~nm}$ (horizontal bar) indicates that the compound might not be acylated.

\subsection{Selection of Two-Phase Solvent System for Purification}

A suitable two-phase solvent system is essential for successful separation by HSCCC. Nonpolar solvents are favored for the isolation of nonpolar target compounds, while polar solvent systems are favored for the isolation of polar compounds. In order to realize efficient separation of the typically hydrophilic anthocyanin compounds, a system of polar solvents was examined. Separation by HSCCC is expressed as its partition coefficient (K), which is usually between 0.4 and 2.5 [20]. A smaller K-value elutes the solute closer to the solvent front at a reduced resolution, while a larger $\mathrm{K}$ value tends to yield a better resolution but with broader, more dilute peaks due to a longer elution time [20].

The biphasic solvent system used in this study was composed of methyl tert-butyl ether/n-butanol/acetonitrile/water/trifluoroacetic acid, which is commonly used for the separation of anthocyanins [30-32]. Since the volume ratio of methyl tert-butyl ether and $n$-butanol has a marked influence on the polarity differential of the two phases, the optimal solvent system was optimized by changing the volume ratio of methyl tert-butyl ether and $n$-butanol. The results demonstrated that methyl tert-butyl ether/ $n$-butanol/acetonitrile/water/trifluoroacetic acid (3.5:0.5:1:5:0.01, $v / v)$ was suitable for separation of the main anthocyanin components from crude A. sessiliflorus anthocyanins (CAA).

\subsection{HSCCC Separation}

The HPLC detection of CAA at $280 \mathrm{~nm}$ indicated that it contained several compounds (Figure 3). While no attempts were made to identify all peaks in Figure 3A, the peak that eluded at approximately 20 min was subsequently identified as cyanidin 3-xylosyl-galactoside (see Figures 3B and 4). The relative concentration of anthocyanin compounds in the crude sample was $13.9 \%$. Figure 4 shows the result obtained from $100 \mathrm{mg}$ of the crude sample by semi-preparative HSCCC. The compounds that eluded between 80 and $90 \mathrm{~min}$, as seen in Figure 4, possessed no color and were therefore not considered to be anthocyanins. The eluent associated with the shaded part of the peak was collected and concentrated. This separation yielded $13.1 \mathrm{mg}$ of anthocyanins at $96.1 \%$ purity based on HPLC analysis, with a mass recovery greater than $90 \%$. 

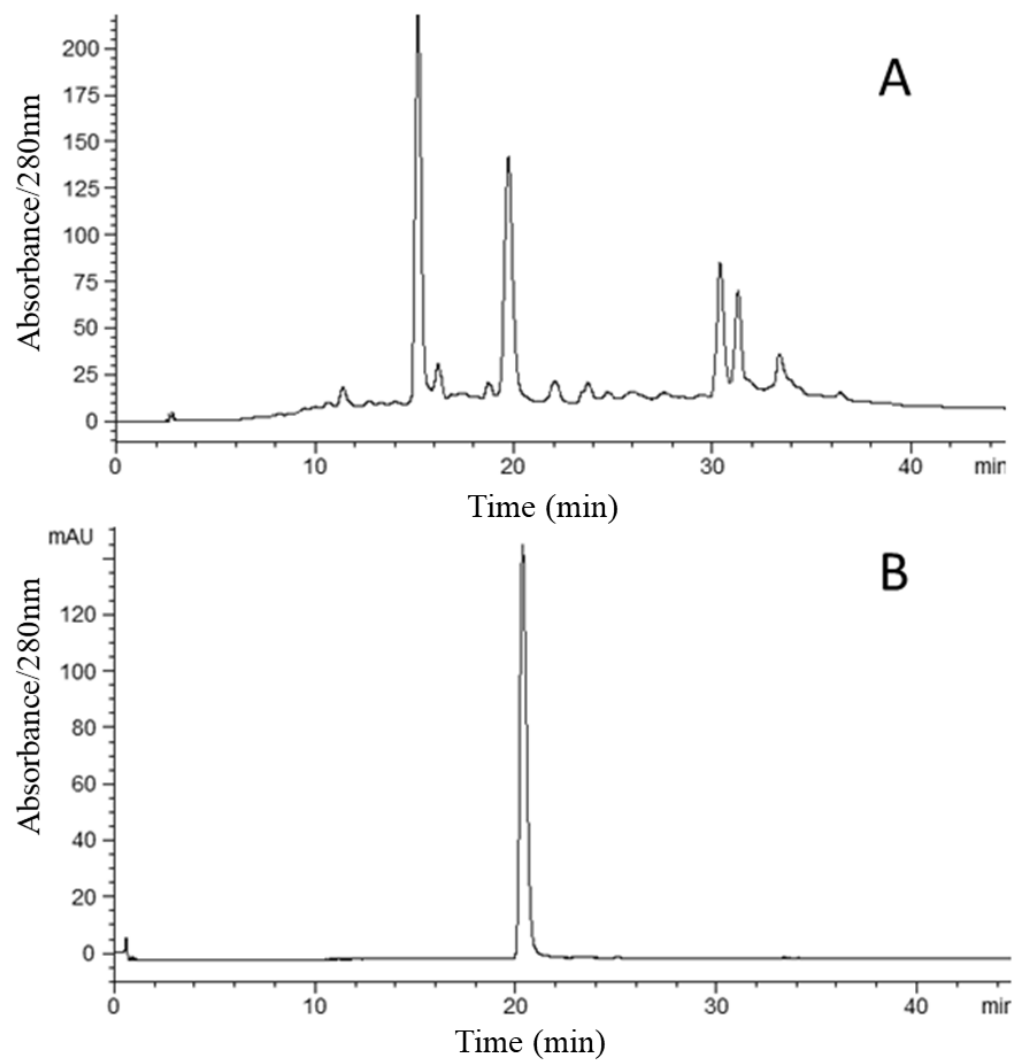

Figure 3. HPLC chromatograms at $280 \mathrm{~nm}$. (A) Chromatogram of the Acanthopanax sessiliflorus acidified methanol extract; (B) cyanidin 3-xylosyl-galactoside from Acanthopanax sessiliflorus following purification by means of high-speed counter-current chromatography (HSCCC) (Figure 4).

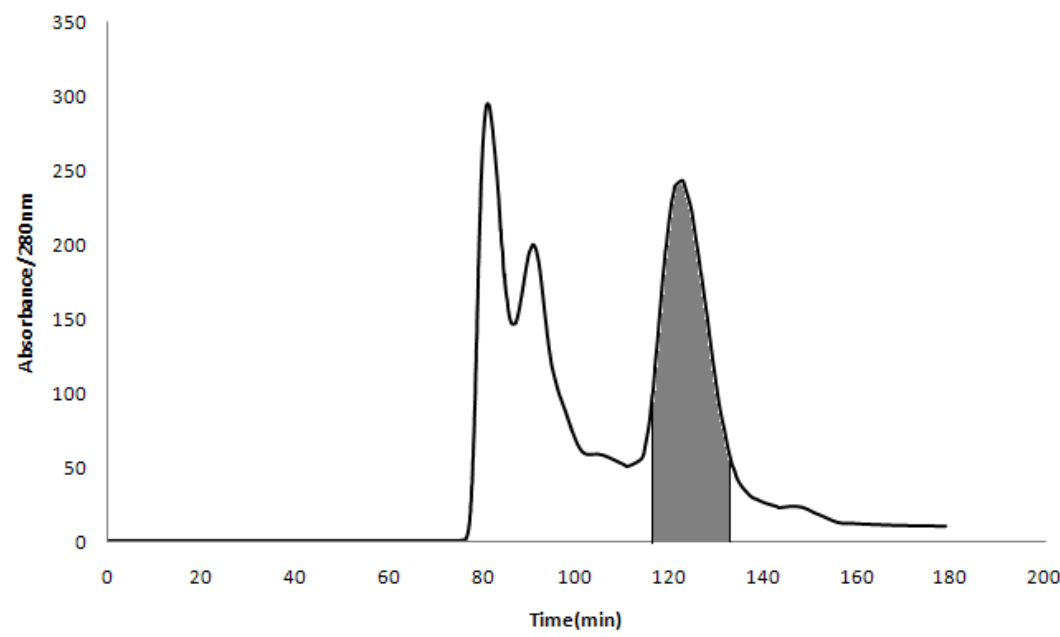

Figure 4. HSCCC chromatogram of the extract from Acanthopanax sessiliflorus (Rupr. \& Maxim.) Seem. The shaded peak represents the fraction of cyanidin 3-xylosyl-galactoside.

\subsection{Confirmation of Anthocyanin Compound}

To confirm the chemical structure of the anthocyanin compound, the fraction purified by HSCCC was subjected to both MS and NMR analyses.

The anthocyanin fraction shown as the greyed out area in Figure 4 was structurally analyzed by ESI-MS. A clear mass spectrum was obtained where an ion at $[\mathrm{M}+\mathrm{H}]^{+} \mathrm{m} / z 583$ indicated the molecular weight of the entire molecule (Figure A1). Based on the $\mathrm{m} / \mathrm{z}$ and fragmentation pattern in this study and similar analysis from other studies [25], the anthocyanin was tentatively labeled as cyanidin 
3-xylosyl-galactoside. As the fragmentor voltage was increased, a decrease in the relative intensity of the putative cyanidin 3-xylosyl-galactoside ion was observed (data not shown). However, the increase in the fragmentor voltage did result in an increase in a mass ion of $m / z 287$, corresponding to the core cyanidin structure of anthocyanidin $[33,34]$. This positively charged aglycone was most likely formed by the loss of the putative disaccharide moiety (xylose and galactose) from Cya-3-Xyl-Gal.

In order to determine the sugar moiety and the linkage patterns between the cyanidin core and the sugar groups, the purified primary anthocyanin (Figure 4) was further characterized by ${ }^{1} \mathrm{H}$ and ${ }^{13} \mathrm{C}-\mathrm{NMR}$ analyses (Table 1 and Figures A2 and A3). With regard to the ${ }^{1} \mathrm{H}-\mathrm{NMR}$ analysis, the compound showed a singlet at 8.88 and doublets at 6.63 and 6.95 for the flavone aromatic protons 4,6 , and 8 , respectively. The aromatic protons $2^{\prime}, 5^{\prime}$, and $6^{\prime}$ were seen as two doublets and a double doublet at $7.95,6.86$, and 8.23 , respectively, with $J$ values of 2.5 and $9 \mathrm{~Hz}$. The anomeric protons associated with the sugars at 5.39 and 4.71 appeared as doublets with a $J$ value of $7.5 \mathrm{~Hz}$, suggesting a diglycoside moiety with $\beta$-configuration at the anomeric positions. Other protons corresponding to the diglycoside group appeared as three triplets at 4.26, 3.79, and 3.03, consistent with one, two, and two protons, respectively. The spectrum also contained two doublets at 3.98 and 3.84 , along with three double doublets at 3.91, 3.17, and 3.64. A multiplet was seen in the spectrum at 3.35. Many anthocyanins contain glucose within the sugar moiety $[25,26]$. In our data analysis we favored galactose as the hexose within the diglycoside because of the typical chemical shifts and coupling constants at $2^{\prime \prime}, 3^{\prime \prime}$, and $4^{\prime \prime}$ in Cya-3-Xyl-Gal $[35,36]$ compared to the typical chemical shifts and coupling constants at 2", 3", and 4" associated with glucose in Cya-3-Xyl-Glu [29]. Furthermore, our ${ }^{13}$ C-NMR spectral data revealed 15 carbons associated with the cyanidin aglycone portion and 11 carbons associated with the sugar moiety. The ${ }^{13} \mathrm{C}-\mathrm{NMR}$ shifts correlatde very well with the ${ }^{1} \mathrm{H}-\mathrm{NMR}$ data, especially in regard to the aromatic and carbohydrate carbon observations. The molecular mass of $m / z 583$ alongside the observed NMR spectral data corresponded very closely to previously reported results $[29,37,38]$. As a result of the combined MS and NMR data, the purified fraction was upheld to be cyanidin 3-xylosyl-galactoside (Figure 5).

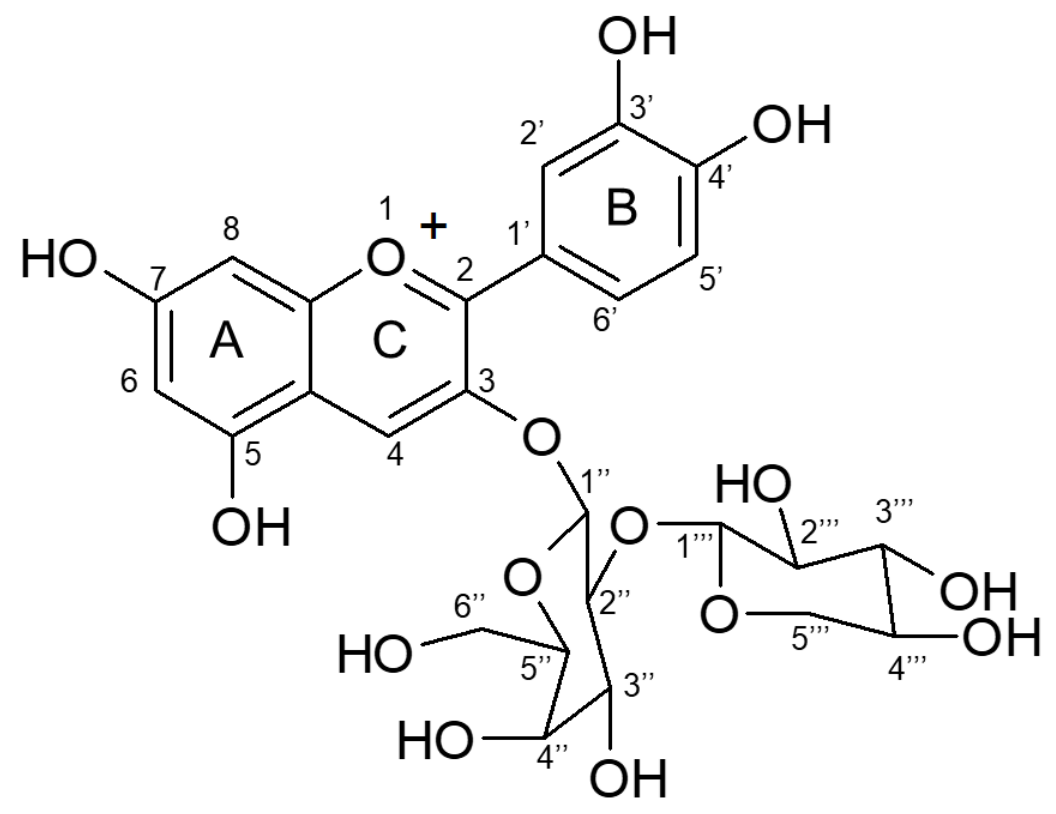

Figure 5. Chemical structure of cyanidin 3-xylosyl-galactoside based on ESI-MS, ${ }^{13} \mathrm{C}$, and ${ }^{1} \mathrm{H}$ analyses.

In addition, the molar absorptivity $(\varepsilon)$ of Cya-3-Xyl-Gal $(\mathrm{MW}=583)$ was determined and calculated to be $16,900 \mathrm{~L} /(\mathrm{mol} \cdot \mathrm{cm})$ from the slope of the plot between $\lambda_{\max }(530 \mathrm{~nm})$ over a concentration range of $0-0.05 \mathrm{mmol} / \mathrm{L}$. 
Cya-3-Xyl-Gal was previously reported in A. sessiliflorus [25], the berries of the Angelica tree (Aralia elata) and Spikenard (Aralia cordata) [39], and black carrot (Daucus carota L.) [40,41]. In black carrot, Cya-3-Xyl-Gal was typically the second most abundant anthocyanin, while it appeared to be the dominant anthocyanin in the berries [25,39].

Table 1. ${ }^{13} \mathrm{C}$ and ${ }^{1} \mathrm{H}$ NMR spectral data (ppm) for cyanidin 3-xylosyl-galactoside.

\begin{tabular}{|c|c|c|}
\hline Cyanidin 3-Xylosyl-Galactoside & $\begin{array}{c}{ }^{13} \mathrm{C}(\mathrm{ppm}) \\
\text { Also Figure } \mathrm{A} 2\end{array}$ & $\begin{array}{c}{ }^{1} \mathrm{H}(\mathrm{ppm}) \\
\text { Also Figure } \mathrm{A} 3\end{array}$ \\
\hline \multicolumn{3}{|l|}{ aglycone } \\
\hline 2 & 164.08 & \\
\hline 3 & 145.33 & \\
\hline 4 & 136.12 & $8.88 \mathrm{~s}$ \\
\hline 5 & 159.18 & \\
\hline 6 & 103.41 & $6.63 \mathrm{~d} 2.0$ \\
\hline 7 & 170.34 & \\
\hline 8 & 95.00 & $6.95 \mathrm{~d} 9.5$ \\
\hline 9 & 157.47 & \\
\hline 10 & 113.19 & \\
\hline $1^{\prime}$ & 121.25 & \\
\hline $2^{\prime}$ & 118.58 & $7.96 \mathrm{~d} 2.5$ \\
\hline $3^{\prime}$ & 147.29 & \\
\hline $4^{\prime}$ & 155.78 & \\
\hline $5^{\prime}$ & 117.39 & $6.86 \mathrm{~d} 1.0$ \\
\hline $6^{\prime}$ & 128.59 & $8.23 \mathrm{dd} 2.5,9.0$ \\
\hline \multicolumn{3}{|l|}{ galactose } \\
\hline $1^{\prime \prime}$ & 102.10 & $5.39 \mathrm{~d} 7.5$ \\
\hline $2^{\prime \prime}$ & 80.02 & $4.26 \mathrm{t} 9.0$ \\
\hline $3^{\prime \prime}$ & 75.10 & $3.91 \mathrm{dd} 3.5,9.5$ \\
\hline $4^{\prime \prime}$ & 70.06 & $3.98 \mathrm{~d} 3.0$ \\
\hline $5^{\prime \prime}$ & 77.70 & $3.84 \mathrm{~d} 9.0$ \\
\hline $6 A^{\prime \prime}$ & 62.33 & $3.81 \mathrm{~d} 3.5$ \\
\hline $6 \mathrm{~B}^{\prime \prime}$ & & 3.79 t5.5 \\
\hline \multicolumn{3}{|l|}{ xylose } \\
\hline $1^{\prime \prime \prime}$ & 106.01 & $4.71 \mathrm{~d} 7.5$ \\
\hline $2^{\prime \prime \prime}$ & 75.81 & $3.17 \mathrm{dd} 8.0,9.0$ \\
\hline $3^{\prime \prime \prime}$ & 77.87 & $3.35 \mathrm{~m}$ \\
\hline $4^{\prime \prime \prime}$ & 70.97 & $3.64 \mathrm{dd} 5.0,11.50$ \\
\hline $5^{\prime \prime \prime}$ & 67.16 & $3.73 \mathrm{~d} 2.0$ \\
\hline $6^{\prime \prime \prime}$ & & $3.03 \mathrm{t} 11.0$ \\
\hline
\end{tabular}

\subsection{Antioxidant Activity of Cyanidin 3-Xylosyl-Galactoside}

The antioxidant activity of Cya-3-Xyl-Gal was investigated and compared to an equimolar ascorbic acid control using both 2,2-diphenyl-1-picrylhydrazyl (DPPH) and ferric-reducing antioxidant power (FRAP).

The FRAP assay measures the reduction of ferric iron $\left(\mathrm{Fe}^{3+}\right)$ to ferrous iron $\left(\mathrm{Fe}^{2+}\right)$ due to the presence of antioxidants and is commonly employed for the routine analysis of single antioxidants and total antioxidant activity of plant extracts $[42,43]$. Figure 6 presents the results of the aging curve of the ferric-reducing antioxidant power of Cya-3-Xyl-Gal and ascorbic acid at $0.1 \mathrm{mmol} / \mathrm{L}$. After $40 \mathrm{~min}$ the ferric-reducing reaction reached equilibrium, resulting in FRAP values of the tested Cya-3-Xyl-Gal and standard ascorbic acid of $234.5 \mu \mathrm{mol} / \mathrm{L}$ and $368.0 \mu \mathrm{mol} / \mathrm{L}$, respectively. Cya-3-Xyl-Gal showed higher ferric-reducing power than the equimolar ascorbic acid control. 


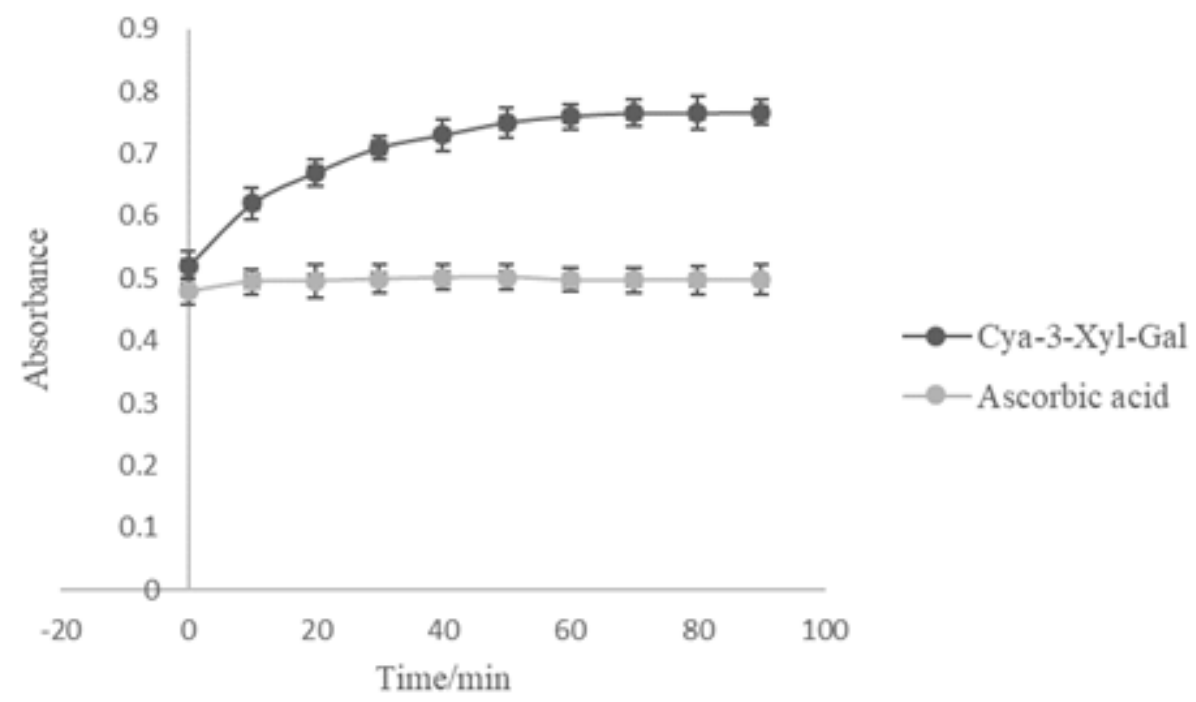

Figure 6. The aging curve of ferric-reducing antioxidant power at $0.1 \mathrm{mmol} / \mathrm{L}$ (ascorbic acid and Cya-3-Xyl-Gal).

The DPPH method is often used to reliably evaluate the free radical scavenging activity of a plant extraction or antioxidant activity due to its stable character [43]. DPPH radical scavenging activity increased with increasing molar concentrations of ascorbic acid and Cya-3-Xyl-Gal (Figure 7). The $\mathrm{IC}_{50}$ values (the antioxidant concentration at which $50 \%$ of the radical scavenging activity was achieved) of Cya-3-Xyl-Gal and ascorbic acid were $0.63 \mathrm{mmol} / \mathrm{L}$ and $0.72 \mathrm{mmol} / \mathrm{L}$, respectively, indicating that the DPPH radical scavenging activity of Cya-3-Xyl-Gal was also greater than that of ascorbic acid.

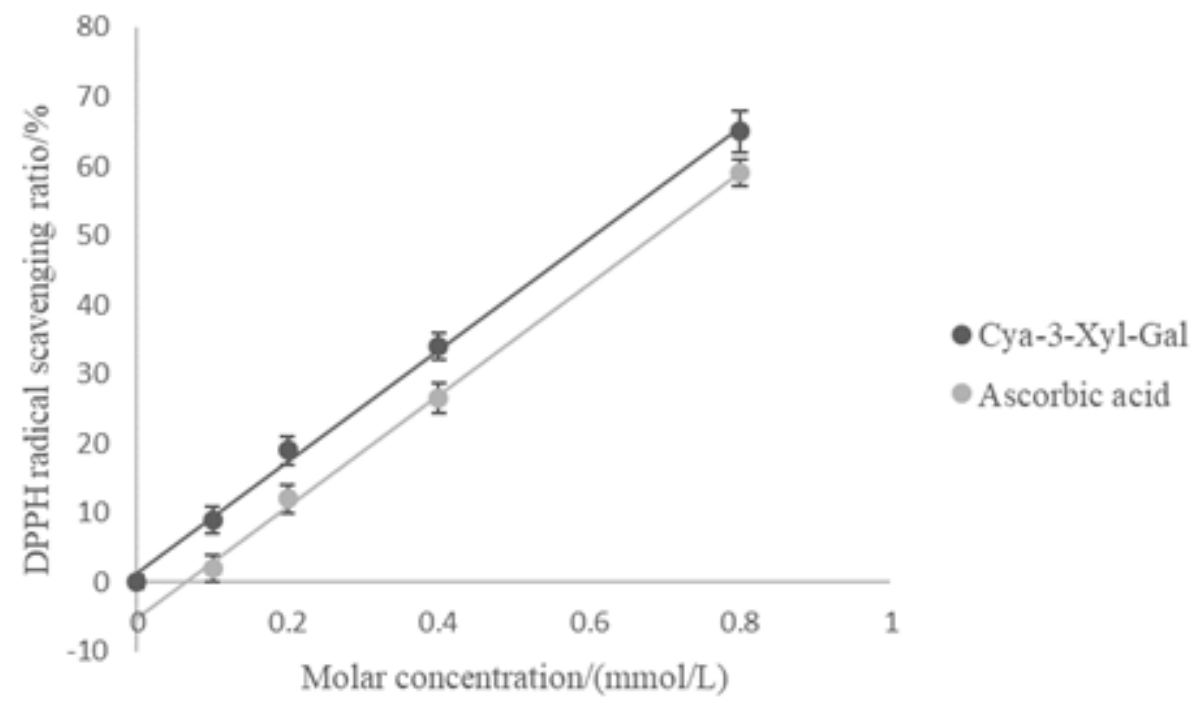

Figure 7. Relationship between the molar concentration of ascorbic acid and Cya-3-Xyl-Gal and DPPH radical scavenging exhaustion for the determination of the $\mathrm{IC}_{50}$ values.

Both antioxidant activity assay methods revealed Cya-3-Xyl-Gal had higher antioxidant activity compared to an equimolar ascorbic acid preparation, implying that Cya-3-Xyl-Gal may be a potent antioxidant. 


\section{Materials and Methods}

\subsection{Chemicals and Reagents}

The fully mature fruits of Acanthopanax sessiliflorus (Rupr. \& Maxim.) Seem. were handpicked from all sides from a number of representative plants in Jilin Province in Northeast China during the period of August to October and stored at $-40{ }^{\circ} \mathrm{C}$ as soon as possible for subsequent chemical analysis. These samples were authenticated by Prof. Liming Zhang at Ningxia Medical University and a voucher specimen (No. Y201107001) deposited at the College of Bioengineering, Beijing Polytechnic.

All organic solvents used were of analytical grade and obtained from Beijing Chemical Factory (Beijing, China). The methanol used for HPLC analysis was of chromatography grade and obtained from Honeywell B\&J (Beijing, China). The standard for cyanidin was obtained from Mansite biological technology Co., Ltd. (Chengdu, China). AB-8 macroporous resin was obtained from Baoen adsorbent material Technology Co., Ltd. (Cangzhou, China).

\subsection{Instruments and Apparatus}

The semi-preparative HSCCC instrument used in this study was a TBE-300A high-speed countercurrent chromatograph (Shanghai Tauto Biotech Co., Ltd., Shanghai, China), which was fitted out and operated as described previously [32]. An HX1050 constant-temperature circulating instrument (Beijing Boyikang Lab Instrument, Beijing, China) was used to maintain a constant separation temperature. A model TBP-50A constant flow pump (Shanghai Tauto Biotech Co., Ltd., Shanghai, China) was employed to supply the solvent into the column, while the eluent was monitored with a model TBD-23UV detector (Shanghai Tauto Biotech Co., Ltd., Shanghai, China).

The analytical HPLC equipment was an Agilent 1100 system [32] fitted with a Zorbax SB-C18 column (250 mm × $4.6 \mathrm{~mm}$, i.d., $5 \mathrm{~mm}$, Agilent Technologies Inc., Shanghai, China).

Electro-spray ionization mass (ESI/MS) analysis and nuclear magnetic resonance (NMR) analysis were carried out by analysts at the Center of Analysis, Beijing University of Chemical Technology, Beijing, China.

\subsection{Total Anthocyanin Determination}

The anthocyanins were thoroughly extracted from three independent $10 \mathrm{~g}$ samples of fresh A. sessiliflorus fruits with methanol acidified with $0.1 \% \mathrm{HCl}$ [32]. The extracts were then analyzed by HPLC. A commercially available standard of cyanidin 3-glucoside was used to create a calibration curve, which yielded a calibration equation of $Y=2233 \times X+13.38\left(R^{2}=0.9999\right)$. The content was expressed as milligrams of cyanidin per $100 \mathrm{~g}$ of fresh weight.

\subsection{Bulk Anthocyanin Extract of A. sessiliflorus}

The fruits of $A$. sessiliflorus ( $1 \mathrm{~kg}$ fresh weight) were extracted with acidified methanol acidified with $0.1 \% \mathrm{HCl}$ at room temperature without continuous agitation for $24 \mathrm{~h}$. This process was repeated three times, after which the extracts were combined. The ratio of the extraction solvent to fruit was 10:1 (v/w). The combined extract was evaporated to form a syrup of about $200 \mathrm{~mL}$. The syrup was diluted to $500 \mathrm{~mL}$ with distilled water acidified with $0.1 \% \mathrm{HCl}$. This aqueous solution was subjected to column chromatography $(45 \mathrm{~mm} \times 50 \mathrm{~cm})$ using an AB-8 macroporous resin in order to separate the anthocyanins. The anthocyanins were eluted under gravity with $1 \mathrm{~L}$ acidified distilled water followed by $2 \mathrm{~L}$ acidified ethanol acidified with $0.1 \% \mathrm{HCl}$. The ethanol elution solution was first evaporated into a syrup and then freeze-dried to yield crude A. sessiliflorus anthocyanins (CAA).

\subsection{Preparation of Two-Phase Solvent Systems and Sample Solutions}

The solvents were mixed in a separation funnel and thoroughly equilibrated by vigorous shaking at room temperature, after which the two phases were allowed to separate. The two phases 
were subsequently degassed by sonication for $20 \mathrm{~min}$ before use. The sample solution for HSCCC was prepared as described previously [32] by dissolving $100 \mathrm{mg}$ of CAA into a $10 \mathrm{~mL}$ two-phase solvent system.

\subsection{Determination of Partition Coefficients (K)}

The partition coefficients $(\mathrm{K})$ were determined as described previously [44]. Briefly, a small amount of CAA was dropped into a $10 \mathrm{~mL}$ test tube, to which $2 \mathrm{~mL}$ of each phase of the equilibrated two-phase solvent system (methyl tert-butyl ether/n-butanol/acetonitrile/water/trifluoroacetic acid) was added. The tube was shaken vigorously, after which the two phases were allowed to separate. A $1 \mathrm{~mL}$ sample of each phase was removed and the solvents were removed by evaporation, after which the residue of each phase was redissolved in acidified methanol. The resulting solutions were analyzed by HPLC, as described in Section 3.3. The K-values were calculated by the ratio between the peak areas.

\subsection{HSCCC Separation}

HSCCC separation was carried out according to the method previously published [32]. Briefly, we applied a head-tail elution mode with the organic phase as the stationary phase. To start with, the multilayer coiled column was completely filled with the organic phase. The aqueous phase was pumped into the head of the column at a flow rate of $2.0 \mathrm{~mL} / \mathrm{min}$ while running at $850 \mathrm{rpm}$ at $25^{\circ} \mathrm{C}$. The UV detector was set at $280 \mathrm{~nm}$. Samples were injected into the separation column after a hydrodynamic equilibrium was established.

\subsection{Analytical Controls and Structure Elucidation}

Quantitative analysis of the anthocyanins by HPLC were as described previously [32]. UV-Vis absorption spectra were recorded using a photodiode array detector. Spectral measurements were made over the wavelength range 200 600 nm in steps of $2 \mathrm{~nm}$. Anthocyanin components were detected at both $280 \mathrm{~nm}$ and $520 \mathrm{~nm}$.

The purified compound was identified by electron impact MS, ${ }^{1} \mathrm{H}-\mathrm{NMR}$, and ${ }^{13} \mathrm{C}-\mathrm{NMR}$ spectrometry carried out by analysts at the Center of Analysis, Beijing University of Chemical Technology. NMR spectra were performed in $\mathrm{CD}_{3} \mathrm{OD} / \mathrm{CF}_{3} \mathrm{COOD}(95: 5 \mathrm{v} / \mathrm{v})$ using a Bruker high-resolution AV500NMR spectrometer at $500 \mathrm{MHz}$ (Bruker Bio Spin Corporation, Billerica, MA, USA).

\subsection{Determination of Molar Absorptivity of Anthocyanin Component}

The molar absorptivity $(\varepsilon)$ of the anthocyanin component was determined by dissolving a series of known quantities of purified anthocyanin in acidified methanol $(0.1 \% \mathrm{HCl})$. The absorbance of the anthocyanin in this dilution series was measured in a Cary 50 Bio UV-Visible spectrophotometer (Varian, Inc., Palo Alto, CA, USA) at $530 \mathrm{~nm}$ using $1 \mathrm{~cm}$ path length quartz cells at $\lambda_{\max }$.

\subsection{Evaluation of Antioxidant Activity}

The antioxidant capacity of ascorbic acid as a standard reference compound and the purified anthocyanin were determined using in vitro FRAP and DPPH antioxidant assays.

The FRAP assay employed 3 aqueous stock solutions, namely, $0.1 \mathrm{~mol} / \mathrm{L}$ acetate buffer ( $\mathrm{pH}$ 3.6), $10 \mathrm{mmol} / \mathrm{L}$ tripyridyl triazine, and $20 \mathrm{mmol} / \mathrm{L}$ ferric chloride, as described previously [45]. Just prior to use, these solutions were combined $(10: 1: 1, v / v / v)$ to form the FRAP reagent. The FRAP reagent and the samples were mixed thoroughly, after which the absorbance of the reaction mixture was determined at $593 \mathrm{~nm}$ using a Cary 50 Bio UV-Visible spectrophotometer (Varian, Inc., Palo Alto, CA, USA). The total antioxidant capacity of anthocyanin samples and ascorbic acid was determined against a ferrous sulphate standard of known FRAP value over a range of $0 \sim 500 \mu \mathrm{M}$. 
The DPPH assay employed a fresh methanolic DPPH solution as described previously [46]. The freshly prepared DPPH solution was transferred into a plastic cuvette and anthocyanin sample, or ascorbic acid was added. The solution was stirred and left to stand in the dark for $30 \mathrm{~min}$, after which the absorbance was measured at $515 \mathrm{~nm}$. The radical scavenging activity was expressed as the percentage of DPPH radical elimination, which was calculated according to the following equation:

$$
\mathrm{R}(\%)=\left(\mathrm{A}_{0}-\mathrm{A}_{1}\right) / \mathrm{A}_{0} \times 100 \%,
$$

where $\mathrm{R}$ is the radical scavenging activity of a sample, $\mathrm{A}_{0}$ is the absorbance of the sample at the start of the reaction, and $A_{1}$ is the absorbance of the sample at the end of the reaction.

\section{Conclusions}

We identified the principle anthocyanin in Acanthopanax sessiliflorus (Rupr. \& Maxim.) Seem as Cya-3-Xyl-Gal. Confirmation of identity was based on ESI-MS, ${ }^{13} \mathrm{C}-\mathrm{NMR}$, and ${ }^{1} \mathrm{H}-\mathrm{NMR}$ analyses. The gross anthocyanin content of $A$. sessiliflorus was $121.35 \mathrm{mg} / 100 \mathrm{~g}$. The application of HSCCC allowed for the successful separation and purification of the primary anthocyanin, Cya-3-Xyl-Gal, which was subsequently used for antioxidant and radical scavenging testing. Both the in vitro antioxidant and radical scavenging tests (FRAP and DPPH, respectively) demonstrated that Cya-3-Xyl-Gal isolated from A. sessiliflorus possesses potent antioxidant potential.

Author Contributions: Conceptualization, L.C. and X.X.; methodology, L.C. and H.F.; software, X.W.; validation, S.L., Q.C. and H.F.; formal analysis, L.C.; investigation, H.F.; resources, X.X.; data curation, X.W.; writing-original draft preparation, L.C.; writing-review and editing, F.V.; visualization, Q.C.; supervision, F.V. and X.X.; project administration, F.V. and X.X.; funding acquisition, L.C., S.L. and X.X. All authors have read and agreed to the published version of the manuscript.

Funding: The authors acknowledge the Support Plan for the Construction of High-level Teachers in Beijing Municipal Colleges and Universities (2019)-Youth Talent-Liang Chen, the Professional Innovation Team Construction Project of Beijing Vocational College Teachers' Quality Improvement Plan (2019)- Shuangshi $\mathrm{Li}$, the Program of Study of Biotransformation and Pharmacological Activity of Active Compounds in Forsythia (2019Z002-015-KXB) of Beijing Polytechnic, and the Program of Beijing Municipal Natural Science Foundation (2182019) for financial support.

Conflicts of Interest: The authors declare no conflict of interest.

\section{Appendix A}

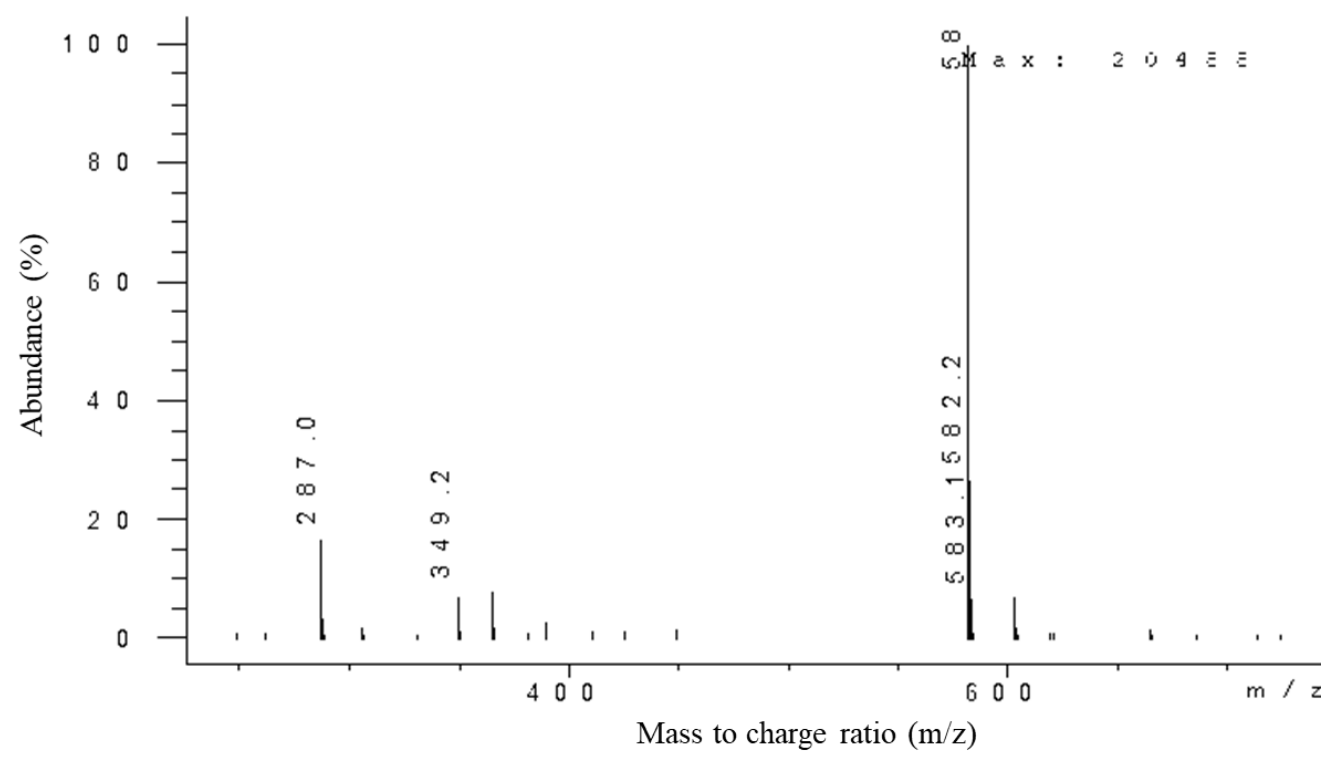

Figure A1. The electro-spray ionization (ESI) mass spectrum obtained from the HSCCC purified fraction. 


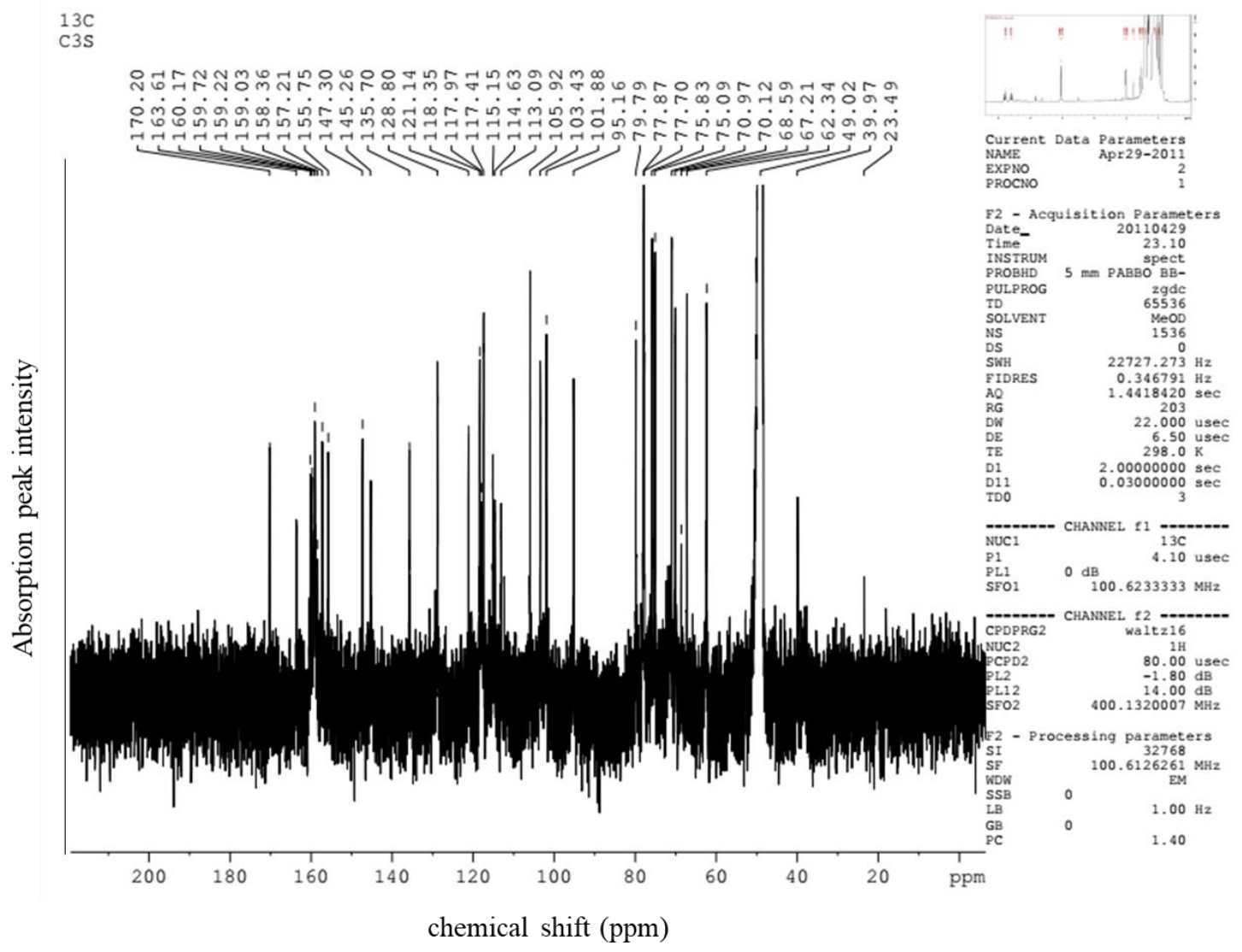

Figure A2. ${ }^{13} \mathrm{C}$ spectral data (ppm) for the HSCCC-purified cyanidin 3-xylosyl-galactoside.

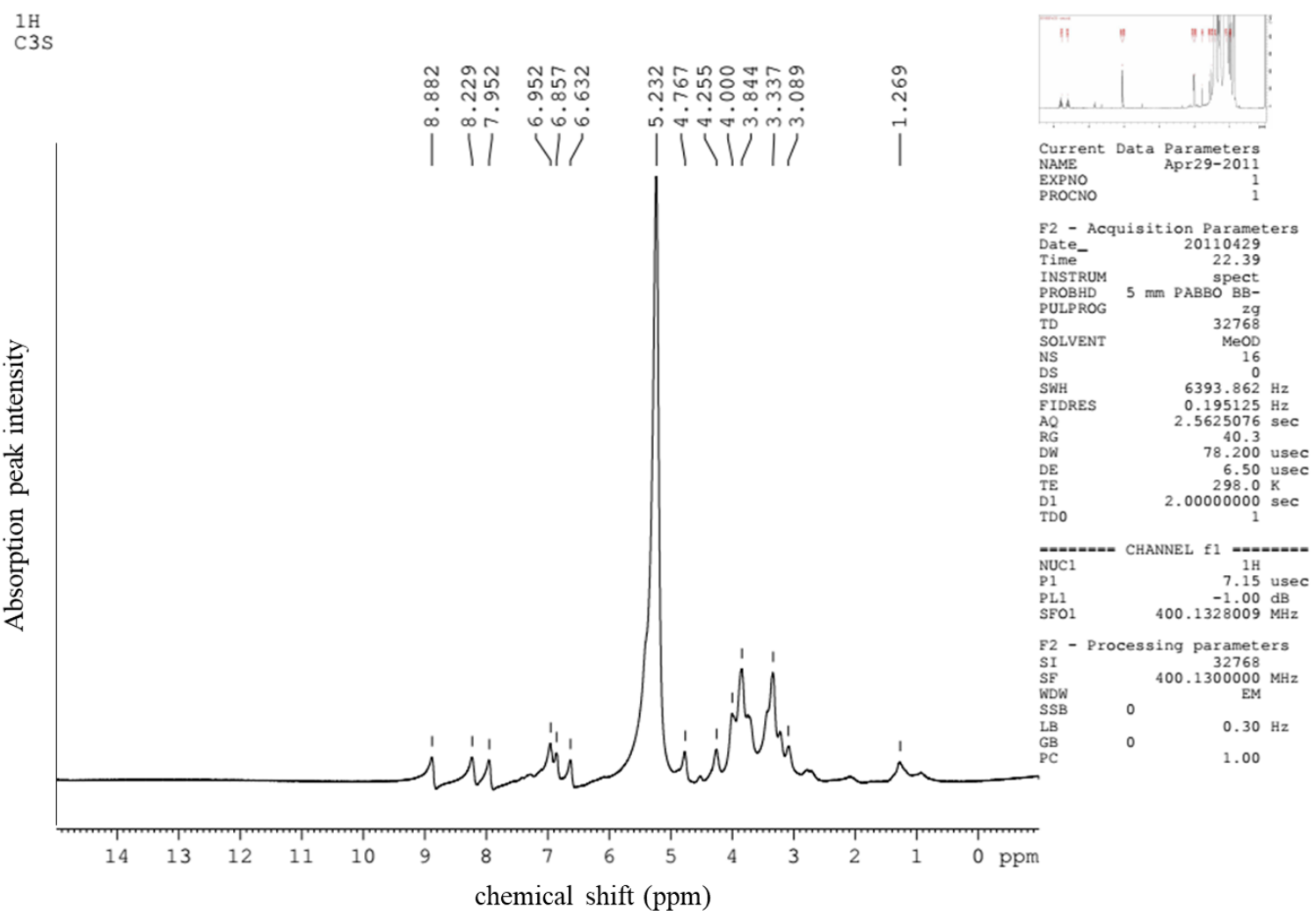

Figure A3. ${ }^{1} \mathrm{H}$ spectral data (ppm) for the HSCCC-purified cyanidin 3-xylosyl-galactoside. 


\section{References}

1. Zhou, C.C. Anti-inflammatory action of ethanol extracts from Acanthopanax sessiliflorus. Chin. J. Chin. Mater. Med. 1985, 10, 37-41.

2. Yoshizumi, K.; Hirano, K.; Ando, H.; Hirai, Y.; Ida, Y.; Tsuji, T.; Tanaka, T.; Satouchi, K.; Terao, J. Lupanetype saponins from leaves of Acanthopanax sessiliflorus and their inhibitory activity on pancreatic lipase. J. Agric. Food Chem. 2006, 54, 335-341. [CrossRef] [PubMed]

3. Yang, C.; An, Q.; Xiong, Z.; Song, Y.; Yu, K.; Li, F. Triterpenes from Acanthopanax sessiliflorus fruits and their antiplatelet aggregation activities. Planta Med. 2009, 75, 656-659. [CrossRef] [PubMed]

4. Meiyu, G.; Yuqiang, L.; Qian, C.; Yutong, L.; Shenlei, Z. Study on the Anti-fatigue Effect of Acanthopanax Sessiliflorus Fruits. Asia-Pac. Tradit. Med. 2015, 19, 6.

5. Billingham, M.; Davies, G. Experimental models of arthritis in animals as screening tests for drugs to treat arthritis in man. In Handbook of Experimental Pharmacology; Springer: Berlin/Heidelberg, Germany, 1979; Volume 50, pp. 108-144.

6. Deyama, T.; Nishibe, S.; Nakazawa, Y. Constituents and pharmacological effects of Eucommia and Siberian ginseng. Acta Pharmacol. Sin. 2001, 22, 1057-1070.

7. Lee, S.H.; Jung, S.H.; Shin, K.H.; Kang, S.S. Antitumor and immunostimulating activities of Acanthopanax sessiliflorus fruits. Nat. Prod. Sci. 2003, 9, 112-116.

8. Jeong, S.C.; Jeong, Y.T.; Yang, B.K.; Song, C.H. Chemical characteristics and immuno-stimulating properties of biopolymers extracted from Acanthopanax sessiliflorus. BMB Rep. 2006, 39, 84-90. [CrossRef]

9. Sumiyoshi, M.; Kimura, Y. Effects of Eleutherococcus sicentosus cortex on recovery from the forced swimming test and fatty acid $\beta$-oxidation in the liver and skeletal muscle of mice. Nat. Prod. J. 2016, 6, 49-55.

10. Bian, X.; Liu, X.; Liu, J.; Zhao, Y.; Li, H.; Zhang, L.; Li, P.; Gao, Y. Hepatoprotective effect of chiisanoside from Acanthopanax sessiliflorus against LPS/D-GalN-induced acute liver injury by inhibiting NF- $\mathrm{B}$ and activating Nrf2/HO-1 signaling pathways. J. Sci. Food Agr. 2019, 99, 3283-3290. [CrossRef]

11. Lee, S.; Kim, B.K.; Cho, S.H.; Shin, K.H. Phytochemical constituents from the fruits of Acanthopanax sessiliflorus. Arch. Pharm. Res. 2002, 25, 280-284. [CrossRef] [PubMed]

12. Han, Y.; Li, Y.; Cui, L.; Pei, K.; Li, F. Determination of the contents of seopoletin and isofraxidin in fruit of Acanthopanax sessiliflorus (Rupr. et Maxim.) Seem. by HPLC. J. Shenyang Pharm. Univ. 2006, 9, 6.

13. He, F.; Han, Y.; Liu, M.; Liu, R.; Li, F. Determination of the contents of total coumarin and 6, 7-dimethoxycoumarin in fruit of Acanthopanax sessiliflorum (Rupr. et Maxim.) Seem. J. Shenyang Pharm. Univ. 2006, 1, 5 .

14. Yang, C.; An, Q.; Song, Y.; Xiong, Z.; Li, F. Isolation and identification of chemical constituents of fruits of Acanthopanax sessiliflorus. China J. Chin. Mater. Med. 2009, 34, 715.

15. Yang, C.; Yu, K.; Song, Y.; Qin, F.; Li, F. Determination and pharmacokinetic study of chiisanogenin in rat plasma by ultra-performance liquid chromatography-tandem mass spectrometry. Phytochem. Anal. 2011, 22, 225-229. [CrossRef] [PubMed]

16. Jun, W.J.; Seong, H.S.; Chun, H.; Lim, E.J.; Kim, K.I.; Cho, H.Y. Determination of antioxidative potentials of Acanthopanax sessiliflorus (Rupr. \& Maxim.) Seem. in differentiated HL-60 cells. Food Chem. 2007, 105, 1557-1563.

17. Tsuda, T. Dietary anthocyanin-rich plants: Biochemical basis and recent progress in health benefits studies. Mol. Nutr. Food Res. 2012, 56, 159-170. [CrossRef]

18. Liang, H.; Li, C.; Yuan, Q.; Vriesekoop, F. Application of high-speed countercurrent chromatography for the isolation of sulforaphane from broccoli seed meal. J. Agric. Food Chem. 2008, 56, 7746-7749. [CrossRef]

19. Oka, F.; Oka, H.; Ito, Y. Systematic search for suitable two-phase solvent systems for high-speed counter-current chromatography. J. Chromatogr. A. 1991, 538, 99-108. [CrossRef]

20. Ito, Y. Golden rules and pitfalls in selecting optimum conditions for high-speed counter-current chromatography. J. Chromatogr. A. 2005, 1065, 145-168. [CrossRef]

21. Marston, A.; Hostettmann, K. Developments in the application of counter-current chromatography to plant analysis. J. Chromatogr. A. 2006, 1112, 181-194. [CrossRef]

22. Friesen, J.B.; Pauli, G.F. Rational development of solvent system families in counter-current chromatography. J. Chromatogr. A. 2007, 1151, 51-59. [CrossRef] 
23. Kan, X.; Yan, Y.; Ran, L.; Lu, L.; Mi, J.; Zhang, Z.; Li, X.; Zeng, X.; Cao, Y. Ultrasonic-assisted extraction and high-speed counter-current chromatography purification of zeaxanthin dipalmitate from the fruits of Lycium barbarum L. Food Chem. 2020, 310, 125854. [CrossRef]

24. Feger, W.; Brandauer, H.; Gabris, P.; Ziegler, H. Nonvolatiles of commercial lime and grapefruit oils separated by high-speed countercurrent chromatography. J. Agric. Food Chem. 2006, 54, 224-252. [CrossRef]

25. Chen, L.; Xin, X.; Yuan, Q.; Su, D.; Liu, W. Phytochemical properties and antioxidant capacities of various colored berries. J. Sci. Food Agr. 2014, 94, 180-188. [CrossRef]

26. Chen, L.; Xin, X.; Zhang, H.; Yuan, Q. Phytochemical properties and antioxidant capacities of commercial raspberry varieties. J. Func. Foods. 2013, 5, 508-515. [CrossRef]

27. Victor, H.; Ronald, E.W. Use of HPLC separation/photodiode array detection for characterization of anthocyanins. J. Agric. Food Chem. 1990, 38, 708-715.

28. Harborne, J. Spectral methods of characterizing anthocyanins. Biochem. J. 1958, 70, 22-28. [CrossRef]

29. Kim, D.M.; Bae, J.S.; Lee, D.S.; Lee, H.; Joo, M.H.; Yoo, S.H. Positive effects of glycosylated anthocyanin isolated from an edible berry fruit (Acanthopanax sessiliflorum) on its antioxidant activity and color stability. Food Res. Int. 2011, 44, 2258-2263. [CrossRef]

30. Degenhardt, A.; Knapp, H.; Winterhalter, P. Separation and purification of anthocyanins by high-speed countercurrent chromatography and screening for antioxidant activity. J. Agric. Food Chem. 2000, 48, 338-343. [CrossRef]

31. Du, Q.; Jerz, G.; Winterhalter, P. Isolation of two anthocyanin sambubiosides from bilberry (Vaccinium myrtillus) by high-speed counter-current chromatography. J. Chromatogr. A. 2004, 1045, 59-63. [CrossRef]

32. Chen, L.; Xin, X.; Lan, R.; Yuan, Q.; Wang, X.; Li, Y. Isolation of cyanidin 3-glucoside from blue honeysuckle fruits by high-speed counter-current chromatography. Food Chem. 2014, 152, 386-390. [CrossRef]

33. Mullen, W.; Lean, M.E.; Crozier, A. Rapid characterization of anthocyanins in red raspberry fruit by high-performance liquid chromatography coupled to single quadrupole mass spectrometry. J. Chromatogr. A. 2002, 966, 63-70. [CrossRef]

34. Tian, Q.; Giusti, M.M.; Stoner, G.D.; Schwartz, S.J. Screening for anthocyanins using high-performance liquid chromatography coupled to electrospray ionization tandem mass spectrometry with precursor-ion analysis, product-ion analysis, common-neutral-loss analysis, and selected reaction monitoring. J. Chromatogr. A. 2005, 1091, 72-82. [CrossRef]

35. Sakamoto, K.; Iida, K.; Sawamura, K.; Hajiro, K.; Asada, Y.; Yoshikawa, T.; Furuya, T. Effects of nutrients on anthocyanin production in cultured cells of Aralia cordata. Phytochemistry 1993, 33, 357-360. [CrossRef]

36. Asada, Y.; Sakamoto, K.; Furuya, T. A minor anthocyanin from cultured cells of Aralia cordata. Phytochemistry 1994, 35, 1471-1473. [CrossRef]

37. Schwarz, M.; Wray, V.; Winterhalter, P. Isolation and identification of novel pyranoanthocyanins from black carrot (Daucus carota L.) juice. J. Agric. Food Chem. 2004, 52, 5095-5101. [CrossRef]

38. Sato, K.; Goda, Y.; Yoshihira, K.; Noguchi, H. Structure and contents of main coloring constituents in the calyces of Hibiscus sabdariffa and commercial roselle color. Food Hyg. Soc. Jpn. 1991, 32, 301-307. [CrossRef]

39. Kawano, K.; Sakamura, S. .Cyanidin 3-[O- $\beta-D-X y l o p y r a n o s y l ~(1 \rightarrow 2)-\beta$-D-galactopyranoside] from Aralia elata and Aralia cordata. Agric. Biol. Chem. 1972, 36, 27-32. [CrossRef]

40. Agcam, E.; Akyıldız, A.; Balasubramaniam, V.M. Optimization of anthocyanins extraction from black carrot pomace with thermosonication. Food Chem. 2017, 237, 461-470. [CrossRef]

41. Farr, J.E.; Sigurdson, G.T.; Giusti, M.M. Influence of cyanidin glycosylation patterns on carboxypyranoanthocyanin formation. Food Chem. 2018, 259, 261-269. [CrossRef]

42. Katalinic, V.; Milos, M.; Kulisic, T.; Jukic, M. Screening of 70 medicinal plant extracts for antioxidant capacity and total phenols. Food Chem. 2006, 94, 550-557. [CrossRef]

43. Dudonne, S.; Vitrac, X.; Coutiere, P.; Woillez, M.; Mérillon, J.M. Comparative study of antioxidant properties and total phenolic content of 30 plant extracts of industrial interest using DPPH, ABTS, FRAP, SOD, and ORAC assays. J. Agric. Food Chem. 2009, 57, 1768-1774. [CrossRef]

44. Zhou, H.; Lv, J.; Yuan, Q. Preparative isolation and purification of punicalin from pomegranate husk by high-speed countercurrent chromatography. Sep. Purif. Technol. 2010, 72, 225-228. [CrossRef] 
45. Benzie, I.F.; Strain, J.J. The ferric reducing ability of plasma (FRAP) as a measure of "antioxidant power": The FRAP assay. Anal. Biochem. 1996, 239, 70-76. [CrossRef]

46. Brand, W.W.; Cuvelier, M.; Berset, C. Use of a free radical method to evaluate antioxidant activity. LWT-Food Sci. Technol. 1995, 28, 25-30. [CrossRef]

Sample Availability: Due to the current epidemic situation, samples are temporarily unavailable.

(C) 2020 by the authors. Licensee MDPI, Basel, Switzerland. This article is an open access article distributed under the terms and conditions of the Creative Commons Attribution (CC BY) license (http://creativecommons.org/licenses/by/4.0/). 